\title{
Comparison of the efficacy of laser-activated and ultrasonic-activated techniques for the removal of tricalcium silicate-based sealers and gutta-percha in root canal retreatment: a microtomography and scanning electron microscopy study
}

\author{
Ruiqi Yang ${ }^{1,2+}$, Yuqing Han ${ }^{1,2+}$, Zhaohui Liu ${ }^{1,2}$, Zhezhen Xu ${ }^{1,2}$, Hongyan Liu ${ }^{1,2^{*}}$ and Xi Wei ${ }^{1,2^{*}}$
}

\begin{abstract}
Background: Tricalcium silicate-based sealers have been usually indicated for the single-cone technique and result in more residual filling materials in root canal retreatment. Passive ultrasonic irrigation and photon-initiated photoacoustic streaming have been reported to improve the removal efficacy of root canal filling materials. However, the abilities of both techniques combined with NiTi re-instrumentation to remove residual tricalcium silicate-based sealer and gutta-percha have not been compared. The aim of this study was to evaluate the efficacy of laser-activated and ultrasonic-activated techniques in vitro for the removal of the tricalcium silicate-based sealer iRoot SP and gutta-percha after standard canal retreatment procedures with the use of nickel-titanium (NiTi) rotary instruments.
\end{abstract}

Keywords: Passive ultrasonic irrigation, Photon-initiated photoacoustic streaming, Endodontic retreatment, iRoot SP, Micro-CT, Scanning electron microscopy

\section{Methods}

Thirty-six extracted single-rooted teeth were filled using a single-cone technique with GP and iRoot SP sealer. These root canals were then retreated using the ProTaper Universal retreatment (PTUR) system. The samples were divided into three groups according to the final irrigation techniques used in retreatment procedures: group 1, classic syringe-based irrigation (CSI); group 2,

*Correspondence: liuhyan@mail.sysu.edu.cn; weixi@mail.sysu.edu.cn

${ }^{\dagger}$ Ruiqi Yang and Yuqing Han have contributed equally to this study.

${ }^{1}$ Department of Operative Dentistry and Endodontics, Guanghua

School of Stomatology, Hospital of Stomatology, Sun Yat-sen University,

Guangzhou, Guangdong Province, China

Full list of author information is available at the end of the article passive ultrasonic irrigation (PUI); and group 3, photoninitiated photoacoustic streaming (PIPS). All groups were irrigated with $2.5 \%$ sodium hypochlorite and 17\% EDTA solutions. Micro-CT scans were taken to evaluate the volume of root filling materials. The cleanliness of root canal walls was scored by scanning electron microscopy (SEM).

\section{Results}

All groups had residual root filling materials in the root canals after mechanical retreatment. Additional use of PIPS removed significantly higher volume of root fillings than PUI and CSI techniques $(p<0.05)$. SEM scores were significantly lower in the PIPS group than in the PUI and

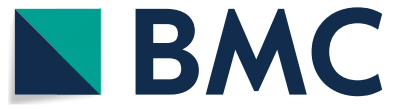

(c) The Author(s) 2021. This article is licensed under a Creative Commons Attribution 4.0 International License, which permits use, sharing, adaptation, distribution and reproduction in any medium or format, as long as you give appropriate credit to the original author(s) and the source, provide a link to the Creative Commons licence, and indicate if changes were made. The images or other third party material in this article are included in the article's Creative Commons licence, unless indicated otherwise in a credit line to the material. If material is not included in the article's Creative Commons licence and your intended use is not permitted by statutory regulation or exceeds the permitted use, you will need to obtain permission directly from the copyright holder. To view a copy of this licence, visit http://creativecommons.org/licenses/by/4.0/. The Creative Commons Public Domain Dedication waiver (http://creativecommons.org/publicdomain/zero/1.0/) applies to the data made available in this article, unless otherwise stated in a credit line to the data. 
CSI groups, especially in the middle and apical thirds $(p<0.05)$.

\section{Conclusions}

None of the additional techniques in this study completely removed the residual iRoot SP and gutta-percha. Compared to PUI and CSI, activation of $2.5 \%$ sodium hypochlorite and 17\% EDTA with PIPS greatly improved the removal of the residual iRoot SP and gutta-percha following NiTi mechanical retreatment.

\section{Background}

Nonsurgical root canal retreatment is an important treatment for persistent periapical periodontitis. The procedures involve reaccessing the root canal system, complete removal of root filling materials, disinfection and root canal refilling to allow periradicular healing [1-3]. Filling materials remaining on the root canal walls can harbor microorganisms and lead to retreatment failure. Removal of the existing root filling materials is therefore key for the long-term success of root canal retreatment, and can be affected by the type of retreatment technique. Several techniques have been used for removing root filling materials including solvents, hand instruments, ultrasonic instruments and nickel-titanium (NiTi) rotary systems [4-6]. The use of NiTi rotary files such as ProTaper Universal retreatment (PTUR) rotary files, is favored over the use of traditional hand instruments due to the lower amount of time required for retreatment procedures [7]. Passive ultrasonic irrigation (PUI) is an ultrasonic-activated treatment modality for removing bacteria, smear layers and dental debris $[8,9]$ through acoustic streaming and cavitation with noncutting action to irrigation solution in the root canal. Some researchers have reported that ultrasonic irrigation for retreatment had a superior effect on removing the sealer and smear layer after post space preparation [10-12]. PUI used after NiTi rotary instruments enhanced the removal of the filling materials more than the use of Reciproc R25 or TS2 alone [13]. However, neither PUI nor NiTi instrumentation can completely remove the gutta-percha and sealers from root canals [14].

iRoot SP (Innovative Bioceramix, Vancouver, BC, Canada), also known as EndoSequence BC Sealer (BC Sealer, Brasseler USA, Savannah, GA, USA), is a novel tricalcium silicate-based sealer with favorable biocompatibility and antibacterial properties. Because high temperature can influence the setting time, flow and porosity of iRoot SP, it is usually indicated for the single-cone technique [15]. Canals obstructed with the single-cone technique always contain a larger amount of sealer than those treated with other filling techniques, such as lateral and warm vertical techniques [16]. Some researchers have demonstrated that $\mathrm{BC}$ sealer resulted in more residual filling materials than AH Plus in root canal retreatment [17]. Simsek et al. found that iRoot SP and/or gutta-percha could not be completely removed by R-endo and ultrasonic irrigation and that canals in all groups tended to amass more debris in the apical third. Therefore, a more effective technique should be developed in future investigations [18].

Photon-initiated photoacoustic streaming (PIPS) is a new laser-activated technique that is used with a lowenergy erbium: yttrium-aluminum-garnet (Er:YAG) laser to activate the irrigant in the root canal [19]. PIPS allows for deeper penetration in dentinal tubules of irrigant and can disinfect the dentinal tubules [20,21]. Studies have reported that PIPS can remove the smear layer and debris more effectively than syringe-based irrigation and ultrasonic activation [22, 23]. PIPS uses only a laser fiber tip placed inside the access cavity, avoiding the risk of thermal damage of the teeth and periodontal tissue. The combined use of PIPS with a NiTi rotary system to remove AH Plus, MTA Fillapex and EndoSequence BC is more effective than the use of NiTi alone [24]. PIPS performs better than ultrasonic techniques in removing $\mathrm{AH}$ Plus sealer from oval root canals [25]. However, to the best of our knowledge, the abilities of laser and ultrasonic-activated techniques combined with NiTi re-instrumentation to remove residual tricalcium silicate-based sealer and gutta-percha have not been compared.

This study was aimed to assess the effectiveness of PIPS and PUI for the removal of iRoot SP sealer and gutta-percha after mechanical retreatment. Classic syringe-based irrigation(CSI) was used as a negative control. Microcomputed tomography (micro-CT) and scanning electron microscopy (SEM)-based quantification of residual filling materials were used to evaluate the removal of filling materials and the cleanliness of the root canal walls. The null hypothesis tested was that there was no significant difference among the three retreatment techniques.

\section{Methods \\ Sample size calculation}

Based on the data of a previous study [26], the sample size in the present study was calculated by the PASS 15 software (Power Analysis \& Sample Size, NCSS, USA). In the ANOVA study, sample size of 12,12 and 12 were obtained from the 3 groups. The total sample of 36 subjects achieves $86 \%$ power to detect differences with a 0.0500 significance level.

\section{Sample selection}

The study was approved by the local ethics committee (KQEC-2020-07) and written informed consent was obtained from all patients. Thirty-six extracted human teeth with completely developed apices and a single straight 
root canal were selected for the study. Micro-CT (Scanco Medical, Zurich, Switzerland) scan was performed to verify a single root canal with a curvature less than $15^{\circ}$ angle and a ratio of the buccolingual to mesiodistal dimensions of less than 2:1 at $5 \mathrm{~mm}$ from the root apex for each tooth $[27,28]$. Teeth with previous root canal treatment, calcification, and resorption were excluded. Specimens were stored in a $0.5 \%$ chloramine-T solution at $4{ }^{\circ} \mathrm{C}$ until use.

\section{Root canal preparation}

Straight access cavities were prepared with a diamond fissure bur SF-41(MANI, INC., Japan) under cooling with water spray. All the teeth were decoronated with the same bur, and the root was cut to a $13 \mathrm{~mm}$ length. Working length (WL) was determined by subtracting $1 \mathrm{~mm}$ from the length at which a size \#10 K-file first appeared at the apical foramen.

The root canals were prepared using ProTaper Next (PTN) rotary instruments (Dentsply, Maillefer, Ballaigues, Switzerland, Switzerland) up to X3 (\#30/0.07) to the WL [24], driven by a torque-controlled motor (SybronEndo, CA, U.S.A.) at $300 \mathrm{rpm}$ with the crown-down technique. The root canals were irrigated by $2 \mathrm{~mL}$ of $2.5 \%$ sodium hypochlorite $(\mathrm{NaOCl})$ (Disineer, Shandong, China) with a 30-gauge side-vented needle (United Dental, Shanghai, China) between each instrument. The final irrigation was $2 \mathrm{~mL} 17 \%$ ethylenediaminetetraacetic acid (EDTA) (Longly, Wuhan, China) for $1 \mathrm{~min}$, followed by $2 \mathrm{~mL}$ of $2.5 \% \mathrm{NaOCl}$ for $1 \mathrm{~min}$ and a rinse with $2 \mathrm{~mL}$ of saline solution for $1 \mathrm{~min}[24,29]$. Then, the root canals were dried with sterile paper points (Dayading, Beijing, China).

\section{Root canal filling}

The canals were obturated using single-cone technique with tricalcium silicate-based sealer-iRoot SP and guttapercha. The sealer was injected into the root canal with a plastic tip, and the tip was slowly pulled toward the orifice from the middle third in the canal. Then, a master cone (Dentsply, Maillefer, Ballaigues, Switzerland, Switzerland) was inserted into the root canal to the $\mathrm{WL}$ and was cut at the orifice level using a heated plugger. The coronal openings were sealed with Caviton (GC, Tokyo, Japan). All samples were then stored at $37{ }^{\circ} \mathrm{C}$ and $100 \%$ relative humidity for 2 weeks to allow complete sealer setting. To avoid the inter-operator variability, the same skilled operator performed all root canal filling.

\section{Root canal retreatment}

\section{ProTaper Universal retreatment (PTUR) rotary} instrumentation

Root canal retreatment was performed using ProTaper Universal retreatment (PTUR) rotary files (Dentsply,
Maillefer, Baillaigues, Switzerland) according to the manufacturer's instructions. The D1 (\#30/0.09), D2 (\#25/0.08) and D3 (\#20/0.07) files were sequentially used for the coronal, middle and apical thirds with the crown-down technique, respectively, and no solvent was used. The root canal was further prepared with PTN X3 (\#30/0.07) and X4 (\#40/0.06) to the WL. Each set of instruments was used for 6 canals. Then, all samples were irrigated with $2 \mathrm{~mL}$ of $17 \%$ EDTA for $1 \mathrm{~min}, 2$ $\mathrm{mL}$ of $2.5 \% \mathrm{NaOCl}$ for $1 \mathrm{~min}$, and $2 \mathrm{~mL}$ of saline solution for $1 \mathrm{~min}$. Irrigation was performed with syringes and 30-gauge side-vented needles. The samples were dried with sterile paper points.

\section{Final irrigation technique}

After instrumentation, the samples were divided into 3 groups according to the random number table method $(\mathrm{n}=12)$ :

Group 1: classic syringe-based irrigation (CSI).

Group 2: passive ultrasonic irrigation (PUI).

Group 3: photon-initiated photoacoustic streaming (PIPS).

Group 1-Classic syringe-based irrigation (CSI).

The root canals were irrigated with $3 \mathrm{~mL}$ of $2.5 \%$ $\mathrm{NaOCl}$ and $3 \mathrm{~mL}$ of $17 \%$ EDTA, for $40 \mathrm{~s}$ respectively with a 30 -gauge side-vented needle. The tip was placed $1 \mathrm{~mm}$ short of the WL and moved up and down within $4 \mathrm{~mm}$ in the root canal. This group was defined as the negative control.

Group 2-Passive ultrasonic irrigation (PUI).

The root canals were irrigated in $5 \mathrm{~s}$ irrigation and then $5 \mathrm{~s}$ activation with 4 times repetitions with $3 \mathrm{~mL}$ of $2.5 \% \mathrm{NaOCl}$. The activation was performed by using a K-type noncutting ultrasonic size 15 tip (Satelec Acteon, Mérignac, France) at 30\%-unit power. The ultrasonic tip was placed $1 \mathrm{~mm}$ short of the WL without touching the root canal walls. After that, $3 \mathrm{~mL}$ of $17 \%$ EDTA was introduced into the root canals using the same procedure. The contact time of each solution with dentin surfaces was standardized at $40 \mathrm{~s}$.

Group 3-Photon-initiated photoacoustic streaming (PIPS).

The root canals were sequentially rinsed with $3 \mathrm{~mL}$ of $17 \%$ EDTA and $3 \mathrm{~mL}$ of $2.5 \% \mathrm{NaOCl}$ and were activated by an Er:YAG laser (Fotona, Ljubljana, Slovenia) with a $300-\mu \mathrm{m}$ endodontic fiber tip $(20 \mathrm{~mJ}, 15 \mathrm{~Hz}, 50-\mu$ s pulse, average power, $0.3 \mathrm{~W}$ ). The tip was placed in the access cavity. The irrigation and activation process were performed using the same protocols in Group 2. Finally, the root canals of the three groups were irrigated with $3 \mathrm{~mL}$ of distilled water and dried with sterile paper points. A single operator prepared all specimens. 


\section{Micro-CT analysis}

The specimens were scanned with a Scanco $\mu \mathrm{CT} 50$ micro-CT (Scanco Medical, Brüttisellen, Switzerland) four times during the treatment: before instrumentation, after the root canal filling, after mechanical retreatment and after the final irrigation procedures. Silicone moulds were created and served as a sample container that allowed for scanning teeth in the same position during the scanning procedure. All samples were scanned at the same position and radiation settings with a voxel size of $34.4 \mu \mathrm{m}, 250$ projections, $70 \mathrm{kV}$, and $57 \mathrm{~mA}$. The volume of the filling materials was measured with Mimics Research 20.0 software. The removed volume for the filling materials used in the final irrigation procedures was calculated by subtracting the volume of the remaining filling materials after the final irradiation procedures from the volume of the remaining filling materials after the mechanical retreatment.

\section{Scanning electron microscopy evaluation}

After micro-CT scanning, scanning electron microscopy (SEM) (Hitachi, Tokyo, Japan) was used to evaluate the cleanliness level of the root canal walls. A shallow longitudinal groove along the buccolingual direction was made in each specimen using a diamond disc (MANI, INC., Japan). A chisel was used to split the teeth into two halves longitudinally. All samples were dehydrated in a desiccator for $24 \mathrm{~h}$ and then sputter-coated with gold (Hitachi, Tokyo, Japan). Then, the coronal, middle and apical thirds of all samples were observed by SEM at $10 \mathrm{kV}$ with a magnification of $1000 \times$. Scanning electron micrographs of at least three randomly selected areas from each sample were taken. The SEM images were scored blindly by two endodontist using modified criteria based on Bernardes et al. and Pirani et al. as follows $[4,30]: 0$, absence of smear layer and filling debris, more than $75 \%$ of the tubules exposed and opened; 1 , smear layer and filling debris present in limited areas, $<75 \%$ of tubules exposed; 2, smear layer and filling debris often present, $<50 \%$ of tubules visibly exposed in a limited area; and 3, smear layer and filling debris present above all dentin, no tubules visible.

\section{Statistical analysis}

The normality and the equality of the data's variance were evaluated using the Shapiro-Wilk test and Levene's test. The Kruskal-Wallis $\mathrm{H}$ test and Mann-Whitney $\mathrm{U}$ test were used to evaluate statistically significant differences of volume of the residual filling materials, volume of the material removed by final irrigation and SEM scores in three parts of the canals among the three groups, and a Friedman and pairwise signed-rank tests were used to compare the difference of root third in each group. The Wilcoxon signed-rank test was used to compare the differences of the volume of remaining filling materials in the coronal, middle and apical thirds before and after the final irrigation-activation technique within each retreatment group. A value of $p<0.05$ was considered statistically significant. The data were analyzed by IBM SPSS Statistics 20.0 (IBM SPSS Inc., Chicago, IL, USA).

\section{Results \\ Micro-CT imaging and analysis of the filling materials}

All specimens had residual filling materials after all treatment procedures (Fig. 1). Median, minimum and maximum values of the volume of the remaining filling materials after mechanical retreatment and after the final irrigation technique are shown in Table 1 . There was no statistically significant difference in the remaining filling materials overall or for each third of the root canal after mechanical retreatment among the three groups $(p>0.05)$. Similar results were observed after final irrigation among the three groups $(p>0.05)$. However, the remaining filling materials after final irrigation in the PUI and PIPS groups were significantly less than those after mechanical retreatment $(p<0.05)$. For the CSI group, there were significantly less residual filling materials in the middle and apical parts than after mechanical retreatment $(p<0.05)$, whereas no significant differences were detected in the coronal third $(p>0.05)$.

The filling materials volume removed by the final irrigation in the three groups is shown in Table 2. Significant differences were observed when comparing the volumes of filling materials removed by the final irrigation technique among the three groups $(p<0.05)$, with the PIPS group showing the most and the CSI group showing the least in the overall canal. PIPS could remove more residual filling materials than CSI and PUI (both $p<0.05$ ) in the coronal third. In the middle and apical thirds, PIPS also removed significantly more residual filling materials than CSI $(p<0.05)$, whereas the difference between the PIPS and PUI groups were not significant (both $p>0.05$ ). Significantly more material was removed in the PUI group than the CSI group in the apical third $(p<0.05)$. In terms of different parts of the root canal under the same final irrigation technique, PIPS and CSI equally removed the residual iRoot SP and gutta-percha in different third of the root canal $(p>0.05)$. PUI removed more residual material in the middle and apical thirds, than in the coronal third $(p<0.05)$.

\section{SEM imaging and evaluation}

Representative SEM images were taken from all canal thirds of the samples (Fig. 2). In the apical third, the CSI group showed a thick smear layer and filling debris 
a1

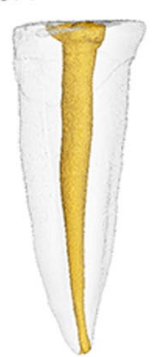

b1

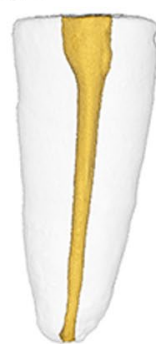

c1

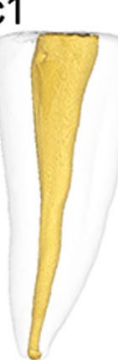

a2
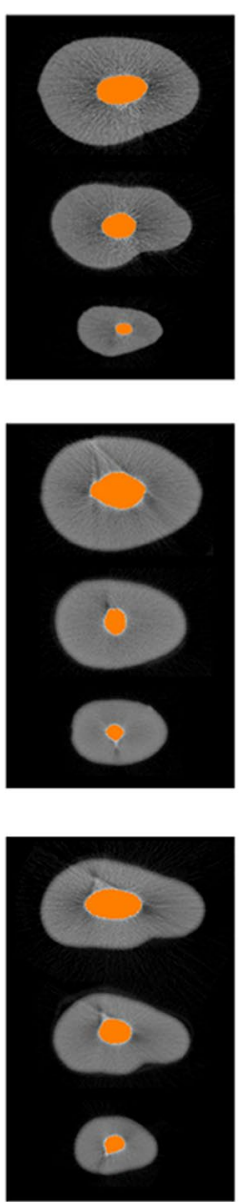

b2
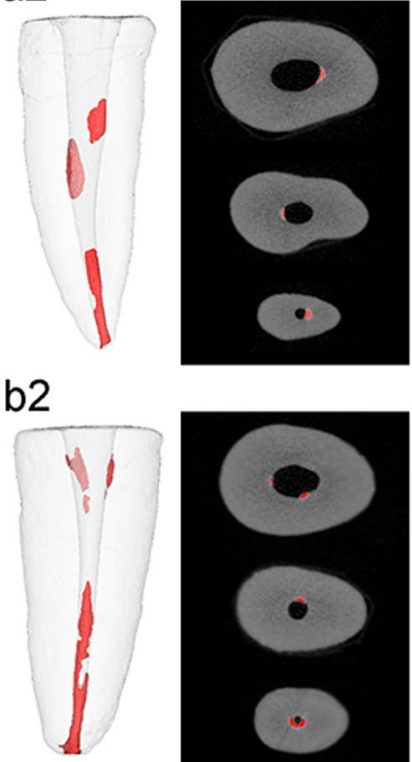

c2
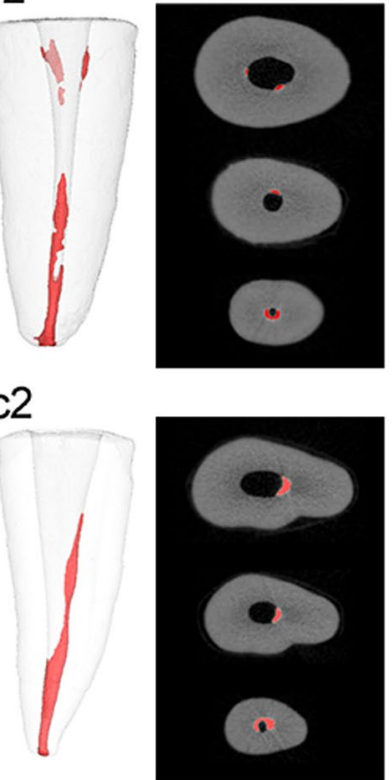

a3

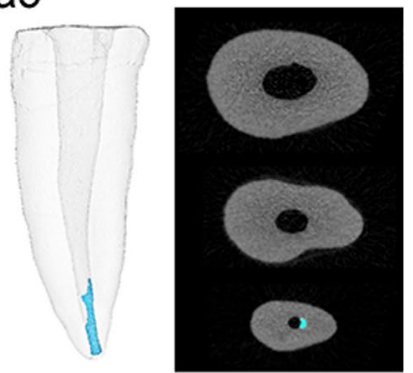

Coronal

b3
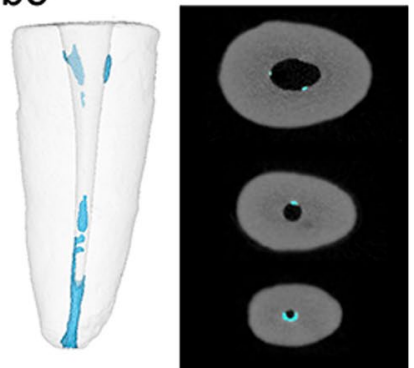

Coronal

Middle

Apical

c3

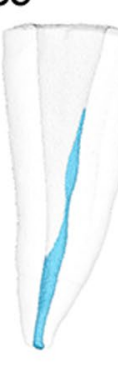

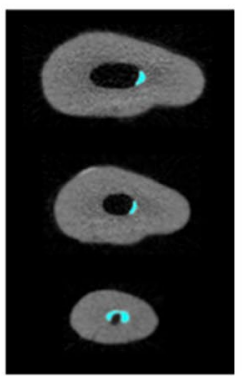

Coronal

Middle

Apical

Fig. 1 Three-dimensional imaging of micro-CT scans of the remaining filling materials: a photon-induced photoacoustic streaming (PIPS) group (a1 after obturation; a2 after mechanical retreatment; $\mathbf{a} 3$ after irrigation); b passive ultrasonic rinsing (PUI) group (b1 after obturation; b2 after mechanical retreatment; b3 after irrigation); c classic syringe-based irrigation (CSI) group (c1 after obturation; $\mathbf{2}$ after mechanical retreatment; c3 after irrigation)

Table 1 Volumes of residual filling materials $\left(\mathrm{mm}^{3}\right)$ measured by micro-CT analysis in each group

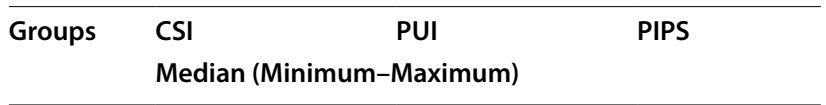

After mechanical instrumentation

Coronal $\quad 0.02(0.00-0.30)^{\mathrm{a}}$

Apical $\quad 0.34(0.04-0.63)^{\mathrm{a}} \quad 0.49(0.00-0.66)^{\mathrm{a}}$

Overall $\quad 0.63(0.12-1.15)^{\mathrm{a}} \quad 0.68(0.09-1.55)^{\mathrm{a}}$

After final irrigation

\begin{tabular}{llll} 
Coronal & $0.01(0.00-0.30)^{\mathrm{a}}$ & $0.01(0.00-0.62)^{\mathrm{b}}$ & $0.01(0.00-0.25)^{\mathrm{b}}$ \\
Middle & $0.14(0.00-0.38)^{\mathrm{b}}$ & $0.04(0.00-0.22)^{\mathrm{b}}$ & $0.06(0.00-0.80)^{\mathrm{b}}$ \\
Apical & $0.33(0.04-0.62)^{\mathrm{b}}$ & $0.39(0.00-0.65)^{\mathrm{b}}$ & $0.23(0.06-0.67)^{\mathrm{b}}$ \\
Overall & $0.52(0.08-1.15)^{\mathrm{b}}$ & $0.50(0.03-1.19)^{\mathrm{b}}$ & $0.44(0.20-1.43)^{\mathrm{b}}$ \\
\hline
\end{tabular}

ab Ranking: statistically significant differences among after mechanical retreatment and after final irrigation in the CSI, PUI and PIPS groups $(p<0.05)$
Table 2 Volumes of residual filling materials $\left(\mathrm{mm}^{3}\right)$ removed by the final technique measured by micro-CT analysis in each group

\begin{tabular}{llll}
\hline Groups & CSI & PUI & PIPS \\
& \multicolumn{2}{l}{ Median (Minimum-Maximum) } & \\
\hline Coronal & $0.03(0.00-0.09)^{\mathrm{a} 1}$ & $0.02(0.00-0.05)^{\mathrm{a} 1}$ & $0.10(0.00-0.29)^{\mathrm{a} 2}$ \\
Middle & $0.01(0.00-0.02)^{\mathrm{a} 1}$ & $0.10(0.00-0.59)^{\mathrm{b} 12}$ & $0.14(0.00-0.32)^{\mathrm{a} 2}$ \\
Apical & $0.01(0.00-0.02)^{\mathrm{a} 1}$ & $0.07(0.00-0.19)^{\mathrm{b} 2}$ & $0.06(0.00-0.13)^{\mathrm{a} 2}$ \\
Overall & $0.03(0.00-0.67)^{1}$ & $0.14(0.00-0.32)^{2}$ & $0.30(0.09-0.50)^{3}$ \\
\hline
\end{tabular}

ab Ranking: statistically significant differences among the coronal, middle, and apical thirds within the CSI, PUI and PIPS groups $(p<0.05)$

123 Ranking: statistically significant differences among the PIPS, PUI and CSI groups $(p<0.05)$ 
covering nearly all of the canal walls. The PUI group showed some dentinal tubules open and others covered by a thin smear layer and filling debris; less than $50 \%$ of tubules were visibly exposed in a limited area. The PIPS group showed small amounts of smear layer and filling debris and $50 \sim 75 \%$ of dentinal tubules opened. In the middle third, the CSI group showed most of the canal walls covered with smear layer and filling debris, the PUI group showed small amounts of smear layer and filling debris and some dentinal tubules opened, while the PIPS group showed small amounts of smear layer and filling debris and $>75 \%$ of tubules exposed. In the coronal third, the CSI and PUI groups showed small amounts of smear layer and filling debris and $>75 \%$ of dentinal tubules opened, and the PIPS group showed most of the tubules opened and no smear layer and filling debris.

As shown in Table 3, in the coronal third, the scores of the three groups were not significantly different $(p>0.05)$. In the middle and apical thirds, the scores were significantly lower in the PIPS group than in the
Table 3 Median, maximum and minimum SEM scores for cleanliness of the canal walls in each third after each final irrigation-activation technique

\begin{tabular}{llll}
\hline Groups & \multicolumn{1}{l}{ CSI } & \multicolumn{1}{l}{ PUI } & PIPS \\
& \multicolumn{1}{l}{ Median (Minimum-Maximum) } & \\
\hline Coronal & $1(0-2)^{\mathrm{a} 1}$ & $1(0-1)^{\mathrm{a} 1}$ & $0(0-2)^{\mathrm{a} 1}$ \\
Middle & $2(0-2)^{\mathrm{a} 1}$ & $1(0-2)^{\mathrm{a} 2}$ & $1(0-2)^{\mathrm{ab} 3}$ \\
Apical & $3(2-3)^{\mathrm{c} 1}$ & $2(1-3)^{\mathrm{b} 2}$ & $1(0-3)^{\mathrm{b} 3}$ \\
\hline
\end{tabular}

ab Ranking: statistically significant differences among the coronal, middle, and apical thirds within each group $(p<0.05)$

123 Ranking: statistically significant difference among groups $(p<0.05)$

PUI $(p<0.05)$ and CSI groups $(p<0.05)$, and were also significantly lower in the PUI group than in the CSI group $(p<0.05)$. Within each group, the scores of the three thirds were significantly different, with the apical third less than the coronal third $(p<0.05)$. The two examiners had a high intraclass correlation coefficient $(I C C)$ in SEM image evaluation (ICC value $=0.843$ ).

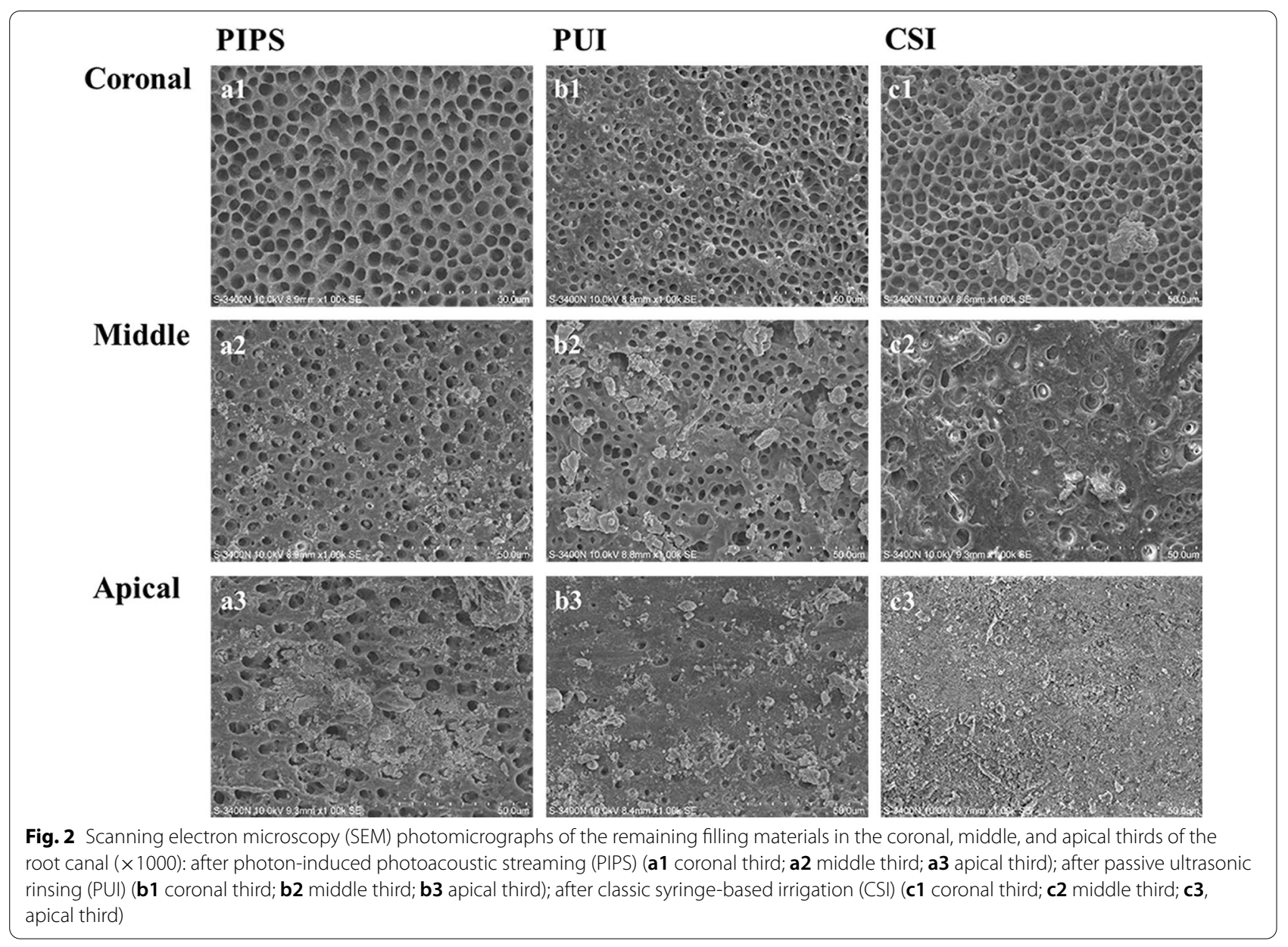




\section{Discussion}

To satisfy periapical healing after root canal retreatment, the previous filling materials should be adequately removed, and the patency and the WL should be established during retreatment [31]. iRoot SP sealer based on a calcium silicate composition has the potential to adhere chemically to dentin [32]. Along the material-dentine interface, calcium silicate-based material could form a tag-like structure that was composed of either $\mathrm{Ca}$ - and P-rich crystalline deposits or the material itself, which may lead to good marginal sealing ability and dentine bonding ability [33]. These may be the reasons for why the $\mathrm{BC}$ sealer has always been found to leave significantly more residual filling materials compared to AH Plus or $\mathrm{AH}-26$ in the root canals obturated by continuous wave compaction technique, single-cone technique or lateral compaction technique $[17,34]$. Oltra et al. used ProFile files to remove the gutta-percha and the $\mathrm{BC}$ sealer in the root canal and found that there was still some sealer remaining in the canal, especially in the apical third [17]. Uzunoglu et al. found that after ProTaper Universal Retreatment instrumentation, residual iRoot SP in the apical and middle thirds of the canals was similar to or higher than the coronal thirds [34]. Therefore, the retreatability of iRoot SP is still a challenge and a more effective technique is needed.

In this study, PUI and PIPS were used as additional methods to remove the residual gutta percha and iRoot SP sealer after mechanical retreatment. Our results demonstrated that none of the additional techniques in this study completely removed the residual iRoot SP and gutta-percha. However, the additional use of PIPS after mechanical retreatment resulted in a significant improvement in removing the iRoot SP and gutta-percha. Similarly, previous studies have shown that PIPS used after NiTi retreatment instruments could improve the removal of the AH plus sealer [23, 25]. Our study also found that PIPS and PUI were superior to CSI in removing residual material from the apical third of the canal. This finding indicated that PIPS and PUI performed effectively as additional techniques after the use of NiTi instrumentation in endodontic retreatment to remove the residual material in the apical canal. SEM results showed that the scores of the three groups were not significantly different in the coronal third, while in the middle and apical thirds, the cleanness levels of the three groups were significantly different, with the PIPS group showed the best cleanliness, and the CSI group showed the worst. All of these findings indicated that PIPS could greatly reduce the smear layer and filling debris on the canal wall and open the dental tubules. Thus the null hypothesis that there was no difference among the three retreatment techniques was rejected.
The better effect of PUI and PIPS on removal of the residual material in the root canals may be related to their mechanism. PUI causes an acoustic flow by producing a rapid circular and swirling motion in the irrigants, and induces a cavitation effect around the ultrasonic file [35]. Similarly, the laser used for PIPS irradiates the irrigant; the subsequent vaporization of the irrigant results in the formation of vapor bubbles, which expand and implode with cavitation effects. The irrigant could rush into the bubble from the back, making the imploding bubble become shaped like a sickle [36]. Moreover, a previous study showed that compared with PUI, PIPS could greatly promote the penetration of solution into the dentinal tubules especially in the apical part of the canal. Due to the anatomical conditions and accessibility in the apical area, PIPS might be advantageous in the removal of filling materials in the apical third of the canal, as it does not depend on the insertion depth of a file or probe, such as PUI or CSI used in this study [20]. These factors may be responsible for our finding that in the middle and apical thirds of the canals, cleanness was greater in the PIPS group than in the PUI group.

PIPS for root canal irrigation most commonly used an Er:YAG laser. In some in vitro studies, different parameters of the Er:YAG laser were used for PIPS. Jiang, et al. used an Er:YAG laser with $50 \mathrm{~mJ}, 20 \mathrm{~Hz}, 1 \mathrm{~W}$ to remove $\mathrm{AH}$ Plus sealer and gutta-percha [25]. Keles, et al. used an Er:YAG with $45 \mathrm{~mJ}, 20 \mathrm{~Hz}, 0.9 \mathrm{~W}$ to remove the filling debris from the canal [23]. Since the energy of an Er:YAG laser is greatly absorbed by water, PIPS needs only a low energy to achieve a better activation-irrigation effect. In the clinic, a small energy of $20 \mathrm{~mJ}$ and a short pulse duration are recommended for the Er:YAG laser [37], and the water/gas function needs to be turned off. With a higher power setting (more than $20 \mathrm{~mJ}$ ), splashing of irrigant outside the tooth may occur, which may cause loss of irrigant and ineffective irrigation. Moreover, the irrigation needs to remain in the root canal to avoid direct laser irradiation of the dentin wall, which may cause thermal damage. The results of this study showed that an Er:YAG laser with $20 \mathrm{~mJ}, 15 \mathrm{~Hz}$, and $0.3 \mathrm{~W}$ can effectively clean the tricalcium silicate-based filling materials, consistent with a previous study that found that an Er:YAG laser with these settings could effectively remove AH Plus, EndoSequence BC and MTA Fillapex sealers [24].

$\mathrm{NaOCl}$ and EDTA are the solutions most commonly used as irrigants for root canal irrigation of PIPS [38, 39]. $\mathrm{NaOCl}$ can dissolve organic tissues and disinfect the root canal. The generally used concentration is $0.5-5.25 \%$. However, high-concentration $\mathrm{NaOCl}$ overflowing from the apical foramen may cause severe complications [40]. Our results showed that PIPS with $2.5 \% \mathrm{NaOCl}$ and 17 \%EDTA effectively reduced the smear layer and filling 
debris on the canal wall surface and opened the dentin tubules, thus facilitating irrigant penetration. Therefore, low-concentration $\mathrm{NaOCl}$ could also obtain an ideal effect in endodontic retreatment, which may improve safety. Based on the above, activation of $2.5 \% \mathrm{NaOCl}$ and $17 \%$ EDTA with PIPS could be used as an additional technique to remove residual tricalcium silicate-based sealers and gutta-percha after the use of NiTi instruments in endodontic retreatment.

\section{Conclusions}

None of the additional techniques in this study completely removed the residual iRoot SP and guttapercha. Compared to PUI and CSI, activation of $2.5 \%$ $\mathrm{NaOCl}$ and $17 \%$ EDTA with PIPS greatly improved the removal of the residual iRoot SP and gutta-percha following NiTi mechanical retreatment.

\section{Abbreviations}

NiTi: Nickel-titanium; PTUR: ProTaper Universal retreatment; PUI: Passive ultrasonic irrigation; PIPS: Photon-initiated photoacoustic streaming; Er: YAG:erbium:yttrium-aluminum-garnet; CSI: Classic syringe-based irrigation; micro-CT: Microcomputed tomography; SEM: Scanning electron microscopy; WL: Working length; PTN: ProTaper Next; NaOCl: Sodium hypochlorite; EDTA: Ethylenediaminetetraacetic acid; ICC: Intraclass correlation coefficient.

\section{Acknowledgements}

Not applicable.

\section{Authors' contributions}

Conceived and designed the experiments: $\mathrm{RY}, \mathrm{YH}, \mathrm{HL}$ and $\mathrm{XW}$; Performed the experiments: RY, YH, ZL and ZX; Analyzed the data: RY, YH; Writing - original draft preparation: $\mathrm{RY}, \mathrm{YH}, \mathrm{HL}$; Writing - review and editing: $\mathrm{XW}$. All authors read and approved the final version of manuscript and agreed to be accountable for all aspects of the work.

\section{Funding}

This research was supported by Guangdong Financial Fund for High-Caliber Hospital Construction (Project Number: 174-2018-XMZC-0001-03-0125/A-01, 174-2018-XMZC-0001-03-0125/D-08). The fund was used for the collection and preparation of samples, providing the materials and tests, and editing for proper use of English. The funders had no role in study design, data collection and analysis, writing the manuscript, decision to publish, or preparation of manuscript.

\section{Availability of data and material}

All data are available from the corresponding author upon reasonable request.

\section{Declarations}

\section{Ethical approval and consent to participate}

This study was performed in line with the principles of the Declaration of Helsinki. Approval was granted by the Medical Ethics Committee of Hospital of Stomatology, Sun Yat-sen University (No. KQEC-2020-07) and written informed consent was obtained from all patients.

\section{Consent for publication}

Not applicable.

\section{Competing interests}

The authors declare that they have no competing interests.

\section{Author details}

${ }^{1}$ Department of Operative Dentistry and Endodontics, Guanghua School of Stomatology, Hospital of Stomatology, Sun Yat-sen University, Guangzhou, Guangdong Province, China. ${ }^{2}$ Guangdong Provincial Key Laboratory of Stomatology, Guangzhou, Guangdong Province, China.

Received: 10 November 2020 Accepted: 18 May 2021

Published online: 22 May 2021

\section{References}

1. Saad AY, Al-Hadlaq SM, Al-Katheeri NH. Efficacy of two rotary NiTi instruments in the removal of Gutta-Percha during root canal retreatment. J Endod. 2007;33(1):38-41. https://doi.org/10.1016/j.joen.2006.08.012.

2. Wu MK, Dummer PM, Wesselink PR. Consequences of and strategies to deal with residual post-treatment root canal infection. Int Endod J. 2006;39(5):343-56. https://doi.org/10.1111/j.1365-2591.2006.01092.x.

3. Mickel AK, Chogle S, Liddle J, Huffaker K, Jones JJ. The role of apical size determination and enlargement in the reduction of intracanal bacteria. J Endod. 2007;33(1):21-3. https://doi.org/10.1016/j.joen.2006.08.004.

4. Pirani C, Pelliccioni GA, Marchionni S, Montebugnoli L, Piana G, Prati C. Effectiveness of three different retreatment techniques in canals filled with compacted gutta-percha or Thermafil: a scanning electron microscope study. J Endod. 2009;35(10):1433-40. https://doi.org/10.1016/j. joen.2009.06.002.

5. Canakci BC, Er O, Dincer A. Do the Sealer Solvents Used Affect Apically Extruded Debris in Retreatment? J Endod. 2015;41(9):1507-9. https://doi. org/10.1016/j.joen.2015.02.010.

6. Bhagavaldas MC, Diwan A, Kusumvalli S, Pasha S, Devale M, Chava DC. Efficacy of two rotary retreatment systems in removing Gutta-percha and sealer during endodontic retreatment with or without solvent: $\mathrm{A}$ comparative in vitro study. J Conserv Dent. 2017;20(1):12-6. https://doi. org/10.4103/0972-0707.209075.

7. Dincer AN, Er O, Canakci BC. Evaluation of apically extruded debris during root canal retreatment with several NiTi systems. Int Endod J. 2015;48(12):1194-8. https://doi.org/10.1111/iej.12425.

8. Capar ID, Aydinbelge HA. Effectiveness of various irrigation activation protocols and the self-adjusting file system on smear layer and debris removal. Scanning. 2014;36(6):640-7. https://doi.org/10.1002/sca.21171.

9. Paiva SS, Siqueira JF Jr, Rocas IN, Carmo FL, Ferreira DC, Curvelo JA, Soares RM, Rosado AS. Supplementing the antimicrobial effects of chemomechanical debridement with either passive ultrasonic irrigation or a final rinse with chlorhexidine: a clinical study. J Endod. 2012;38(9):1202-6. https://doi.org/10.1016/j.joen.2012.06.023.

10. Chen X, Liu H, He Y, Luo T, Zou L. Effects of Endodontic Sealers and Irrigation Systems on Smear Layer Removal after Post Space Preparation. J Endod. 2018;44(8):1293-7. https://doi.org/10.1016/j.joen.2018.05.014.

11. Grischke J, Muller-Heine A, Hulsmann M. The effect of four different irrigation systems in the removal of a root canal sealer. Clin Oral Investig. 2014;18(7):1845-51. https://doi.org/10.1007/s00784-013-1161-6.

12. Nguyen TA, Kim Y, Kim E, Shin SJ, Kim S. Comparison of the efficacy of different techniques for the removal of root canal filling material in artificial teeth: a micro-computed tomography study. J Clin Med. 2019. https:// doi.org/10.3390/jcm8070984.

13. Kaloustian MK, Nehme W, El Hachem C, Zogheib C, Ghosn N, Michetti J, Naaman A, Diemer F. Evaluation of two shaping systems and two ultrasonic irrigation devices in removing root canal filling material from mesial roots of mandibular molars: a micro CT study. Dent J. 2019. https://doi. org/10.3390/dj7010002.

14. Rossi-Fedele G, Ahmed HM. Assessment of root canal filling removal effectiveness using micro-computed tomography: a systematic review. J Endod. 2017;43(4):520-6. https://doi.org/10.1016/j.joen.2016.12.008.

15. Qu W, Bai W, Liang YH, Gao XJ. Influence of warm vertical compaction technique on physical properties of root canal sealers. J Endod. 2016;42(12):1829-33. https://doi.org/10.1016/j.joen.2016.08.014.

16. Topcuoglu HS, Ulusan O, Topcuoglu G, Biricik E. Apically extruded debris during the removal of canal filling material from root canals using three techniques. Journal of investigative clinical dentistry. 2018;9(3):e12337. https://doi.org/10.1111/jicd.12337. 
17. Oltra E, Cox TC, LaCourse MR, Johnson JD, Paranjpe A. Retreatability of two endodontic sealers, EndoSequence BC Sealer and AH Plus: a microcomputed tomographic comparison. Restor Dent Endod. 2017;42(1):1926. https://doi.org/10.5395/rde.2017.42.1.19.

18. Simsek N, Keles A, Ahmetoglu F, Ocak MS, Yologlu S. Comparison of different retreatment techniques and root canal sealers: a scanning electron microscopic study. Braz Oral Res 2014, 28. https://doi.org/10.1590/18073107bor-2014.vol28.0006.

19. Peters OA, Bardsley S, Fong J, Pandher G, Divito E. Disinfection of root canals with photon-initiated photoacoustic streaming. J Endod. 2011;37(7):1008-12. https://doi.org/10.1016/j.joen.2011.03.016.

20. Galler KM, Grubmuller V, Schlichting R, Widbiller M, Eidt A, Schuller C, Wolflick M, Hiller KA, Buchalla W. Penetration depth of irrigants into root dentine after sonic, ultrasonic and photoacoustic activation. Int Endod J. 2019;52(8):1210-7. https://doi.org/10.1111/iej.13108.

21. Wang X, Cheng X, Liu X, Wang Z, Wang J, Guo C, Zhang Y, He W. Bactericidal effect of various laser irradiation systems on Enterococcus faecalis biofilms in dentinal tubules: a confocal laser scanning microscopy study. Photomed Laser Surg. 2018;36(9):472-9. https://doi.org/10.1089/pho. 2017.4430.

22. Akyuz Ekim SN, Erdemir A. Comparison of different irrigation activation techniques on smear layer removal: an in vitro study. Microsc Res Tech. 2015;78(3):230-9. https://doi.org/10.1002/jemt.22466.

23. Keles A, Kamalak A, Keskin C, Akcay M, Uzun I. The efficacy of laser, ultrasound and self-adjustable file in removing smear layer debris from oval root canals following retreatment: a scanning electron microscopy study. Aust Endod J. 2016;42(3):104-11. https://doi.org/10.1111/aej.12145.

24. Suk M, Bago I, Katic M, Snjaric D, Munitic MS, Anic I. The efficacy of photon-initiated photoacoustic streaming in the removal of calcium silicatebased filling remnants from the root canal after rotary retreatment. Lasers Med Sci. 2017:32(9):2055-62. https://doi.org/10.1007/s10103-017-2325-4.

25. Jiang S, Zou T, Li D, Chang JW, Huang X, Zhang C. Effectiveness of sonic, ultrasonic, and photon-induced photoacoustic streaming activation of $\mathrm{NaOCl}$ on filling material removal following retreatment in oval canal anatomy. Photomed Laser Surg. 2016;34(1):3-10. https://doi.org/10.1089/ pho.2015.3937.

26. Arslan D, Guneser MB, Dincer AN, Kustarci A, Er K, Siso SH. Comparison of smear layer removal ability of QMix with different activation techniques. J Endod. 2016;42(8):1279-85. https://doi.org/10.1016/j.joen.2016.04.022.

27. Neuhaus KW, Liebi M, Stauffacher S, Eick S, Lussi A. Antibacterial efficacy of a new sonic irrigation device for root canal disinfection. J Endod. 2016:42(12):1799-803. https://doi.org/10.1016/j.joen.2016.08.024.

28. Jensen LE, Murphy S, Williamson AE, Teixeira FB, Johnson WT, Friedl CC, Peters OA. Root canal preparation in mandibular premolars with TRUShape and Vortex Blue: a micro-computed tomography study. Aust Endod J. 2019;45(1):12-9. https://doi.org/10.1111/aej.12322.

29. Keine KC, Kuga MC, Tormin FBC, Vencao AC, Duarte MAH, ChavezAndrade GM, Faria G. Effect of peracetic acid used as single irrigant on the smear layer, adhesion, and penetrability of AH Plus. Braz Oral Res. 2019;33:e057. https://doi.org/10.1590/1807-3107bor-2019.vol33.0057.
30. Bernardes RA, Duarte MAH, Vivan RR, Alcalde MP, Vasconcelos BC, Bramante CM. Comparison of three retreatment techniques with ultrasonic activation in flattened canals using micro-computed tomography and scanning electron microscopy. Int Endod J. 2016;49(9):890-7. https://doi. org/10.1111/iej.12522.

31. Ng YL, Mann V, Gulabivala K. A prospective study of the factors affecting outcomes of nonsurgical root canal treatment: part 1: periapical health. Int Endod J. 2011;44(7):583-609. https://doi.org/10.1111/j.1365-2591. 2011.01872.x.

32. Candeiro GT, Correia FC, Duarte MA, Ribeiro-Siqueira DC, Gavini G. Evaluation of radiopacity, $\mathrm{pH}$, release of calcium ions, and flow of a bioceramic root canal sealer. J Endod. 2012;38(6):842-5. https://doi.org/10.1016/j. joen.2012.02.029.

33. Han L, Okiji T. Uptake of calcium and silicon released from calcium silicate-based endodontic materials into root canal dentine. Int Endod J. 2011:44(12):1081-7. https://doi.org/10.1111/j.1365-2591.2011.01924.x.

34. Uzunoglu E, Yilmaz Z, Sungur DD, Altundasar E. Retreatability of Root Canals Obturated Using Gutta-Percha with Bioceramic, MTA and ResinBased Sealers. Iran Endod J. 2015;10(2):93-8.

35. van der Sluis LW, Versluis M, Wu MK, Wesselink PR. Passive ultrasonic irrigation of the root canal: a review of the literature. Int Endod J. 2007:40(6):415-26. https://doi.org/10.1111/j.1365-2591.2007.01243.x.

36. Blanken J, De Moor RJ, Meire M, Verdaasdonk R. Laser induced explosive vapor and cavitation resulting in effective irrigation of the root canal. Part 1: a visualization study. Lasers Surg Med. 2009;41(7):514-9. https://doi. org/10.1002/lsm.20798.

37. Olivi G, De Moor R, DiVito E: Lasers in Endodontics: Scientific Background and Clinical Applications. In., 1st edn. Cham: Springer International Publishing: Imprint: Springer,; 2016: 1 online resource (X, 298 pages 352 illustrations, 187 illustrations in color.

38. Wen C, Kong Y, Zhao J, Li Y, Yu M, Zeng S, Shi Z, Jiang Q. Efficacy of the photon-initiated photoacoustic streaming combined with different solutions on Enterococcus faecalis in the root canals. Microsc Res Tech. 2020;83(6):647-57. https://doi.org/10.1002/jemt.23455.

39. Zhu X, Yin X, Chang JW, Wang Y, Cheung GS, Zhang C. Comparison of the antibacterial effect and smear layer removal using photon-initiated photoacoustic streaming aided irrigation versus a conventional irrigation in single-rooted canals: an in vitro study. Photomed Laser Surg. 2013;31(8):371-7. https://doi.org/10.1089/pho.2013.3515.

40. Perotti S, Bin P, Cecchi R. Hypochlorite accident during wndodontic therapy with nerve damage: a case report. Acta Biomed. 2018;89(1):1048. https://doi.org/10.23750/abm.v89i1.6067.

\section{Publisher's Note}

Springer Nature remains neutral with regard to jurisdictional claims in published maps and institutional affiliations.

Ready to submit your research? Choose BMC and benefit from

- fast, convenient online submission

- thorough peer review by experienced researchers in your field

- rapid publication on acceptance

- support for research data, including large and complex data types

- gold Open Access which fosters wider collaboration and increased citations

- maximum visibility for your research: over 100M website views per year

At BMC, research is always in progress.

Learn more biomedcentral.com/submissions 